\title{
Research on the Construction of the Network Learning Platform Based on Computer Foundation Course
}

\author{
Ying Luo ${ }^{1, \text { a }}$, Miaomiao $\mathrm{Li}^{2, \mathrm{~b}}$ \\ ${ }^{1}$ Education School,Jiangxi Science \&Technology Normal University, Nanchang, China \\ ${ }^{2}$ Education School,Jiangxi Science \&Technology Normal University, Nanchang, China \\ amooonly@126.com; biMiaomiao0710@163.com
}

Keywords: Network teaching; Intelligent network teaching platform; Multimedia application technology

\begin{abstract}
The paper mainly introduce the intelligent network teaching platform designed and implemented by university computer foundation course network learning platform oriented to language $\mathrm{c} \#$ and based on NET structure, which is connected with ASP.NET technology and ADO.NET technology. This network learning platform plays a very important role in real-time interaction and teaching resources sharing, and shows the advantages of intelligent network teaching platform: intelligent, interactive, open, and free.
\end{abstract}

\section{Introduction}

The design of the intelligent network teaching platform not only displays the latest network education technology level, the more important is to meet the universal requirement and rules of modern network education, to provide high efficiency education methods for the network education.

Forward in the informatization modern society, global scholars have made all kinds of researches. The construction of the modern network education platform has become the important government behavior of many countries, and most countries have their own national network teaching center. Now the most successful model of network teaching is the Open University.

Intelligent network education in our country has experienced decades of development along the rhythm of the world, but compared with advanced countries in the world, in order to create real powerful network education system, we still has great distance. In the face of the challenges and opportunities at the same time, we should actively learn good experience from developed countries of carrying out the remote education, and timely adjust our intelligent network education system.

\section{Feasibility analysis}

Economic feasibility.

Spending: WINDOWS XP / 7, Microsoft visual studio, Microsoft SQL server.

Benefits: intelligent network learning platform solves the problem of slow updating resources, further improves the management efficiency, reduces the personnel utilization, and saves more paper to create good environment.

Technical feasibility.

Asp.net language, as a very mature and normative technology, is an excellent language from the compiled code to execute. It is perfect in the security, standardization and operation. Microsoft SQL server is the very stable and safe database. With the characteristics of stability, safety, and large storage, it has a very high utilization rate in the world; so this system has met the system requirements on the design of the software and hardware.

\section{Feasibility on the running.}

Full consideration to the development and design of the system can make teachers and students more convenient and quick to browse the files, upload and download files, online communication, etc. At the same time, it is more convenient for the administrator to modify teachers and students' information. 


\section{Web site overall planning}

In order to ensure the advantages, reliability and practicability of intelligent network platform, the main design ideas of system are as follows:

In the development and design of the software, we use the original prototype development method to ensure the practicability of the software development, and try to reduce the risk of software development.

Strictly comply with and use the relevant principles of object-oriented, the applicable standards of software engineering, oriented to object technology, to ensure the project rational, structural and consistent, and the software versatile.

The system platform can mainly achieve the function: the showing of students' learning and teachers' teaching resources, uploading and downloading of teaching resources, and interaction in nnlinn nnmmuninntinn raray between the teaching links.

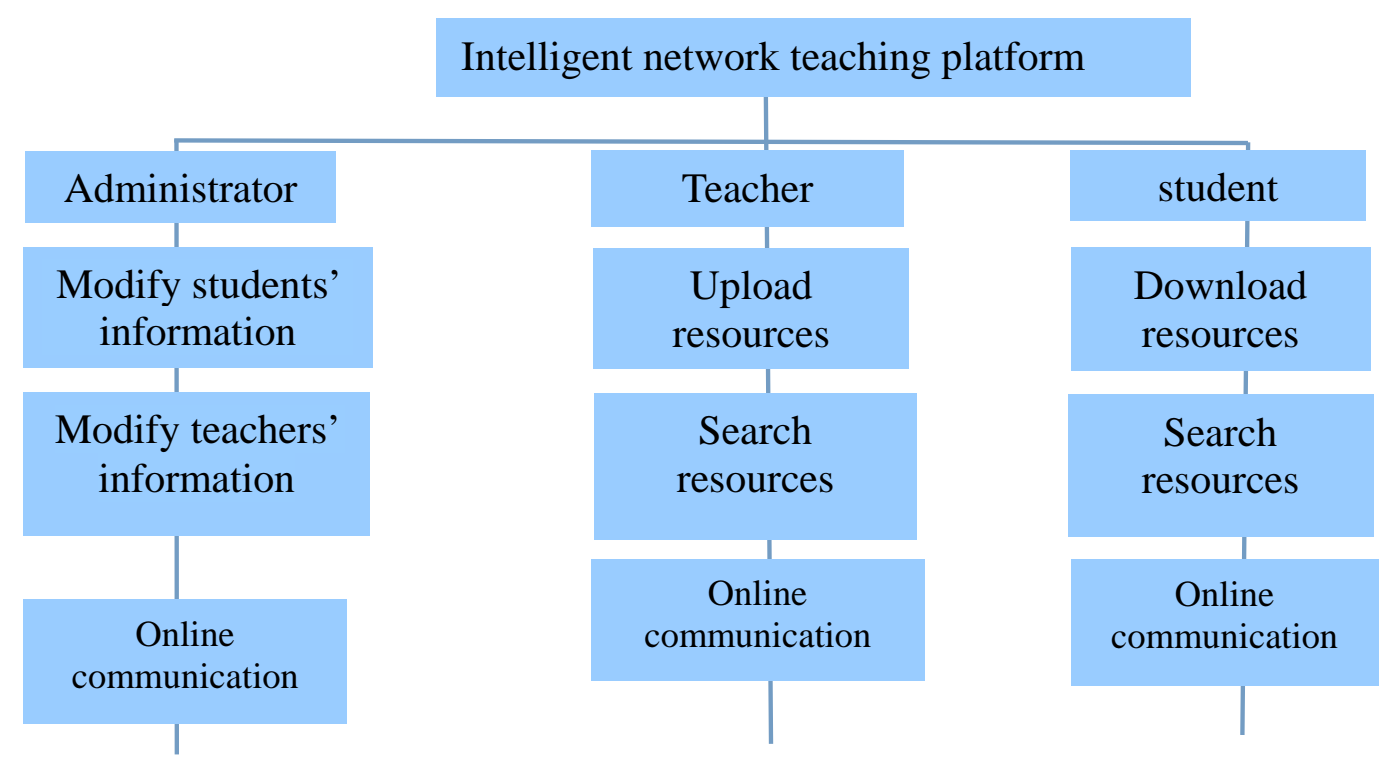

Picture 1: The function module frame

\section{Module functions realization and description}

User registration module:

This module function can mainly register new users. When the user opens the interface, fills in the account and password, and clicks on the register, connect with the database the Users table, judge whether the account name repeats, success if not repeat, and then jump to the log in screen. Parts of the code are as follows:

protected void Button1_Click(object sender, EventArgse)\{

SqlDataReader read = dataconn.ExceRead("select * from Users where Usr_name="' + this.username.Text + "'"');

read.Read();

if (read.HasRows) \{

if (this.username.Text == read["Usr_name"].ToString())

\{

Response.Write("<script>alert('User already exists!') $<$ script $>$ ");

Response.Write("<script>window.location.href='Reg.aspx'</script>"); \}

else if (username.Text == "' || password.Text == "')

\{ 


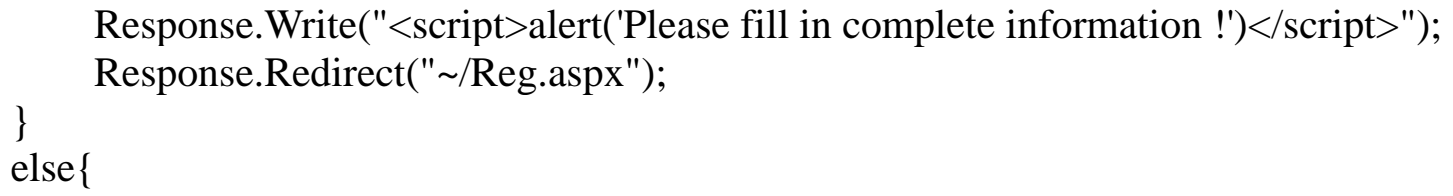

Directory access module:

Obtain the subdirectory method Create ChildNode () is used to put the real user name folder binding to the drop-down list, the implementation code is as follows:

private void Create.ChildNode(DropDownList dirList,DataTable dataTable,int nParentID,string sParentName) \{

DataRow[] rowList = dataTable.Select("Parent.ID="' + nParentID.ToString() + "'","CreateDate DESC");

foreach(DataRow row in rowList) \{ string sName = sParentName + row["Na.me"].ToString() + "/"; dirList.Items.Add(new ListItem(sName,row["Di.rID"].ToString()));

CreateChildNode(dirList,dataTable,Int32.Parse(row["Di.rID"].ToString()),sName \}

\section{Result}

After the user clicks and logs in, the system will determine the user's permissions, and achieve different functions according to the different user permissions. There are three kinds of user permissions, respectively is system administrators, teachers and students.

In the registration, user can register through the user name and password. At the same time, if the user name duplicates at the time of registration, system will pop up error message boxes and prompt invalid user name.

In the administrator page, the administrator can modify the information of the teachers and students, but can not upload and download teaching resources, and access to online communication child pages.

\section{Summary}

The thesis comprehensively systematically introduces the completion process of intelligent network. This web site, of course, still has many shortcomings, but will be improved in the development in the future.

The students can not collect what they like online and read until download, this system still need to improve in this aspect.

The system hasn't achieved the function of online reading, so students can't choose the required course by means of online reading.

The administrator can recommend the courses downloaded most by students and promote good resources; this system still needs to improve in this area.

\section{Reference}

[1] Hongin Geng. The design and implementation of university computer foundation course network teaching platform [D].Tongji university .Software college .2008 
[2] Miao Cui, Liusan Guan, Wei Peng.ASP.NET programming with java(C\# version )[M]. Mechanical industry press.2010.08

[3] jun Ma.C\# program design and application course(second edition).People's posts and telecommunications press[M].2009.05

[4] Zhi-bo Chen.The principle and application of database course(second edition) People's posts and telecommunications press[M].2008.03

[5] Xiaoman Dong.Website construction based on Windows. Tsinghua university press [M].2001.7 